\title{
A implantação oficial da Pedagogia histórico-crítica na rede pública do Paraná
}

Alexandra Vanessa de Moura Baczinski

Professora da Universidade Estadual do Oeste do Paraná

\section{Resumo}

Esta pesquisa tem por objetivo investigar, analisar e contextualizar a iniciativa do estado do Paraná em otimizar seu sistema educacional pela implantação oficial da pedagogia Histórico Critica nos anos 1980 e compreender as contradições e conseqüências dessa política educacional. Buscamos estudar a primeira implantação oficial, desvendar suas intrincadas contradições e identificar suas potencialidades, para então analisar os reais motivos da implantação dessa pedagogia. Utilizaremos, como procedimento metodológico, levantamento bibliográfico, além de entrevistas e análise de documentos. Fundamentando-nos a partir dos pressupostos teórico-metodológicos do materialismo histórico dialético.

Palavras-chave: Pedagogia crítica, Política educacional, Educação - Paraná.

\begin{abstract}
The objective of this research is to investigate, analyze and contextualize the initiative of Parana State on improving the Educational System on the official implantation of Historic Critical Pedagogy in the 1980s also understanding the contradictions and consequences of the educational policy. Thus we try to study the first official implantation, to find out its intricate contradictions and identify its potentialities so that analyze the real reasons of the implantation of the new pedagogy. Used as methodological procedure, bibliography, besides the interviews documental analysis. Our fundaments are theoretical and pedagogical presupposition of the dialectic historical materialism.
\end{abstract}

Keywords: Critical Pedagogy, Educational Policy, Education - Parana 
presente trabalho resulta da pesquisa de mestrado, a qual tem por finalidade investigar como se deu a implantação oficial da Pedagogia Histórico-Crítica no Estado do Paraná. O período estudado é aquele que foi historicamente marcado pelos movimentos sociais de reivindicação e conquista da redemocratização do país, após mais de 20 anos de vigência de um regime de exceção, a denominada ditadura militar. A pesquisa contempla o período entre 1983 a 1994, abrangendo os governos de José Richa, Álvaro Dias, e Roberto Requião, no Estado do Paraná.

A referida pesquisa objetiva explicitar em que grau de comprometimento se deu a implantação da Pedagogia Histórico-Crítica como proposta pedagógica oficial do Estado do Paraná. Quais as reais intenções dos governantes ao assumir tal pedagogia naquele contexto histórico e atmosfera política de contestação e cooptação no cenário político internacional e brasileiro, em vista do esgotamento da intervenção autoritária militar e as exigências de arranjo na ordem jurídica, vida política e sistemas de poder no Brasil.

Os anos 1980 foram cenário de um intenso processo de afirmação da cidadania, luta contra a ditadura militar e conquista de liberdade política e organizacional. São os anos da redemocratização, das eleições livres nos Estados, nas Capitais, a causa da Anistia, afirmações de classes e categorias emancipatórias. A educação e o resgate da escola pública estiveram no centro destas lutas.

A maior intervenção na democracia efetuada pelo Estado CivilMilitar não foi apenas a supremacia do Executivo sobre os demais poderes e a edição de atos institucionais e decretos; o que a tornou mais grave e perigosa foi a cassação de todos os partidos políticos existentes e a criação de dois novos: Aliança Renovadora Nacional (ARENA), representando as forças governistas e o Movimento Democrático Brasileiro (MDB), o qual representava a oposição "consentida" pelo regime militar que, doravante, seriam os canais por que passaria a escolha dos representantes políticos que elaborariam as leis do país.

Apesar das inúmeras tentativas de obter consenso, o governo militar perdia cada vez mais aliados, com isso crescia o grupo de oposição, o qual 
formou a "Aliança Democrática". A referida Aliança constitui-se pela junção entre o PMDB (Partido do Movimento Democrático Brasileiro) - grupo esse que consistiu na "oposição consentida" em todo período do governo militar - dissidentes do PDS (Partido Democrático Social) - grupo aliado ao regime militar - os quais, em oposição ao regime, passaram a compor a sigla PFL (Partido da Frente Liberal).

Nas eleições de 1982, para governador, os partidos de oposição (PMDB e PDT) obtiveram em torno de 5 milhões e 200 mil votos a mais que o partido da situação (PDS). O Partido Democrático Social (PDS) venceu para governador nos Estados do Maranhão, Ceará, Rio Grande no Norte, Paraíba, Pernambuco, Alagoas, Sergipe, Bahia, Mato Grosso, Rio Grande do Sul e Santa Catarina. O Partido do Movimento Democrático Brasileiro (PMDB) foi vitorioso em São Paulo, Minas Gerais, Espírito Santo, Mato Grosso do Sul, Paraná, Goiás, Pará, Amazonas e Acre. E o Partido Democrático Trabalhista (PDT) venceu as eleições no Rio de Janeiro (Germano, 1994). Significando com isso, o fim dos militares no governo, além do domínio que os partidos oposicionistas obtiveram com relação ao Colégio Eleitoral para a escolha do novo Presidente da República em 1985.

Nas referidas eleições de 1982, o Estado do Paraná elegeu o governador José Richa, do então MDB (Movimento Democrático Brasileiro), que representou o início da retomada da democracia, tal como foi entendida no contexto das lutas populares em torno das eleições diretas. Durante o mandato (1983-1986), de José Richa os professores da rede pública, realizaram debates e estudos em torno de uma proposta de educação democrática. Nesse processo de transição política, onde os educadores mobiliavam-se para a universalização da educação pública e de qualidade para todos, construiu-se uma nova proposta educacional, a qual fundamentou-se na concepção da Pedagogia Histórico-Crítica ${ }^{1}$. Tal proposta foi utilizada como fundamento

\footnotetext{
$1 \mathrm{O}$ trabalho de reestruturação do Currículo de $1^{\circ} \mathrm{Grau}$ da Rede Estadual de Ensino teve como ponto de partida a implantação do Ciclo Básico de Alfabetização que, dentro da proposta de Reorganização da Escola Pública de $1^{\circ}$ Grau do Paraná, constitui-se no primeiro passo. Através do envolvimento de professores da rede Estadual e Municipal, representantes dos Núcleos Regionais de Educação, das Inspetorias Estaduais de Educação, dos Cursos de Magistério, da Associação dos Professores do Paraná, Associação Educacional do Oeste do Paraná, da União de Dirigentes Municipais de Educação e das Instituições do En- 
na implantação do Currículo básico para a escola pública do Estado do Paraná, sendo sistematizado em redação final no ano de 1990, no mandato do governador Álvaro Dias, também do PMDB (1987-1990).

Esta proposta de educação, fundamentada na Pedagogia HistóricoCrítica manteve-se até 1994, perdurando por três mandatos subseqüentes (Richa, Álvaro Dias e Roberto Requião). A continuidade governamental não é, por si, penhor da manutenção ou reconhecimento de sua implantação.

Este é o terreno histórico e o recorte temático de nossa pesquisa: como se deram os processos de implantação, convencimento, ordenação institucional da Pedagogia Histórico-Crítica no Paraná? Explicitar as contradições deste período e a política educacional estadual, centrada na Pedagogia HistóricoCrítica, aferir suas repercussões e graus de internalização na rede pública, na estrutura curricular e organizacional da escola é o objetivo central dessa pesquisa.

A relevância do tema justifica-se por contribuir à compreensão da história da educação brasileira e seus condicionantes sociais, políticos e econômicos. Vale lembrar que tal estudo não tem a pretensão de esgotar o tema, mas sim contribuir com o conjunto das pesquisas realizadas no âmbito acadêmico.

Podemos conjunturalmente entender que a transição iniciada nos anos 1980 ainda não foi completada. Encontramo-nos no meio de um processo político de sistematização de novas práticas, instituições e concepções políticas, culturais, sociais e, especialmente educacionais. A educação falida do governo militar ainda não foi restaurada. A LDB de 1996 e os dispositivos oriundos da improvisada reforma educacional brasileira (1996/2002), como parâmetros curriculares nacionais, temas transversais, voluntariado, exame nacional dos cursos, etc. foram insuficientes para uma orgânica transformação da educação pública. Assim nossa questão permanece na pauta política mais genuína: pode uma política educacional revolucionária ou transformadora ser implantada pelos mecanismos oficiais do Estado? Quais são os sujeitos coletivos que forneceriam legitimação a esta pedagohistórico-critica que fundamentam teoricamente esta proposta. (PARANÁ-SEED, 1992, P. 13). 
gia? Assim, buscando estudar a primeira implantação oficial, desvendar suas intrincadas contradições e identificar suas potencialidades não estaremos produzindo uma arqueologia do passado, mas criando um ordenamento criterioso para analisar o estado atual da educação paranaense.

Quanto à natureza metodológica, essa pesquisa constitui-se num trabalho de caráter qualitativo, bibliográfico e documental. Para analisar os dados da pesquisa empírica tomaremos como fundamentação metodológica os pressupostos do materialismo histórico dialético (concepção críticodialética) por entendermos que as concepções de educação estão sempre vinculadas à estrutura da sociedade e, conseqüentemente às políticas públicas em nível internacional, nacional e estadual.

Para responder ao problema proposto à essa investigação abordamos inicialmente o contexto político-econômico paranaense, enfatizando a política educacional proclamada e realizada nos governos pós-ditadura militar. Em seguida buscamos analisar a matriz política e teórica da Pedagogia Histórico-Critica. Para finalizar analisamos de forma crítica os processos, contradições e perspectivas no período de implantação da Pedagogia HistóricoCrítica como pedagogia oficial do Estado do Paraná, buscando apresentar a contradição existente entre os objetivos reais e os objetivos proclamados. Buscamos destacar, nesse processo histórico recente, as conseqüentes intervenções, resistências e legitimações no âmbito da política educacional implantada pelo Estado do Paraná.

Trata-se de um trabalho dissertativo que, longe de ter a pretensão de dissecar o tema e, sobretudo, as contradições que lhe deram origem e sustentação, busca somente auxiliar no esclarecimento histórico, no debate político e na ordenação de princípios e diretrizes para uma efetiva transformação social e relevante conquista de um sistema público de educação e ensino. 


\section{A política educacional do Estado do Paraná: propostas educacionais dos governos peemedebistas de 1983 a 1994}

Nas eleições de 1982, para governadores, os partidos oposicionistas conquistaram grande ascensão política, sendo eleitos com grande vantagem de votos em relação ao partido da situação (PDS). No Estado do Paraná venceu para governador José Richa, com a legenda do PMDB, sendo eleito por sufrágio universal, ou seja, eleito por votação direta.

Para conquistar a vitória política e a supressão do governo militar, o PMDB elaborou e divulgou propostas de redemocratização do Estado, mediante a redemocratização da educação. Nessa proposta, o PMDB posicionase a respeito de diversas questões sociais, econômicas, políticas e educacionais, defendendo concepções contrárias àquelas defendidas pelo governo militar.

Como proposta de redemocratização do Estado, o PMDB apresenta uma nova visão de sociedade e de educação. Defendem que a sociedade constitui-se a partir das relações sociais e que a educação deve ser libertadora, na medida em que ensina conhecimentos científicos, capazes de garantir à classe trabalhadora as condições (conhecimentos) necessárias para superar a condição de dominada.

Mesmo com a superação do Regime Militar, o Estado continua sendo um representante da classe dominante, porém, atua ideologicamente como um Estado defensor dos direitos à igualdade, liberdade de expressão, e democracia. Contudo, não deixou de ser um Estado liberal e capitalista. Por esses motivos é que encontramos na proposta do PMDB a seguinte defesa de política educacional:

Uma política educacional democrática haverá de promover uma dessacralização da escola, atribuindo aos grupos sociais organizados a responsabilidade de forjar seus próprios destinos. Nesse momento é a própria função do Estado e do poder que estará em questão. Os grupos dirigentes despidos de seus poderes autoritários, passarão a ser intérpretes das aspirações e ne- 
cessidades da sociedade civil, como executores da vontade popular (PMDB, 1982, p. 21).

Nas entrelinhas desse discurso democrático - que expressa aspirações do Estado em superar a postura autoritária e centralizadora, para uma postura supostamente democrática de um Estado igualmente democrático, que acata e atende as necessidades da sociedade civil - encontra-se um Estado que continua sendo representante de uma sociedade civil cindida em classes antagônicas. Sendo assim, os grupos sociais organizados constituemse pela classe dominante, a qual tem o Estado como seu representante. Com isso, a "vontade popular" a ser atendida pelo Estado não passará da "vontade" da classe dominante.

Tais esclarecimentos fazem-se necessários para que possamos compreender o processo de redemocratização do Estado assim como da educação escolar. Melhor dizendo, sem desconsiderar todos os fatores e formas de atuação que diferenciam o Estado Democrático-liberal do Estado Militar, devemos ter clareza de que ambos os governos trabalham em favor do desenvolvimento do país de acordo com os padrões do modo de produção capitalista.

Diante desse quadro histórico, inicia-se na década de 1980, o discurso da abertura política, bem como o da democratização da sociedade e da educação nos diferentes níveis de ensino, o que se caracterizava pelo acesso e permanência da população, em idade escolar, na escola. Também se anunciava a função da escola como mediadora do conhecimento científico, ou seja, do conteúdo social e historicamente produzido. Sendo esse o princípio entendido como parâmetro de escola de qualidade.

Torna-se necessário esclarecer se essa proposta representou realmente a redemocratização da sociedade, ou se expressava apenas um discurso para recompor a hegemonia liberal burguesa. Logo, faz-se necessário explicitar o conteúdo da política de governo de José Richa, Álvaro Dias e Roberto Requião. 


\section{Governo José Richa (1983-1986)}

O governo José Richa priorizou a política educacional redimensionando aquilo que, no âmbito das lutas por uma educação pública democrática, se considerava insatisfatório no âmbito qualitativo e quantitativo. Oportunizou a retomada do ensino público gratuito, proporcionou melhores condições de trabalho aos docentes e incentivou a participação popular na escola, o que se constituiu numa das mais profundas características desse governo, a escola aberta e democrática.

No primeiro ano do Governo José Richa, a Secretaria Estadual de Educação (SEED/PR) elaborou um documento norteador das políticas educacionais de Governo, intitulado de "Políticas SEED-PR. Fundamentos e Explicitação/1983”. Os principais objetivos apresentados por esse documento foram o desenvolvimento do compromisso político dos educadores com a maioria da população, também foi destacada a abertura para a participação popular, além de apresentarem uma concepção de Escola aberta e democrática empenhada em ofertar o conhecimento como patrimônio coletivo da sociedade. Enfatizando prioridade ao ensino de primeiro grau.

Tendo em vista os documentos analisados, é possível destacarmos algumas ações relevantes realizadas por esse governo, dentre elas estão: a eleição direta para diretores de escolas de $1^{\circ}$ e $2^{\circ}$ graus. A reformulação dos regimentos escolares, sendo reestruturados a fim de banir as ações autoritárias e antidemocráticas preestabelecidas no período da ditadura militar. A realização da Semana Pedagógica em substituição ao dia de "planejamento escolar". A descentralização dos serviços educacionais, mediante a ampliação de 8 para 22 dos Núcleos Regionais de Educação (NREs). A ampliação do apoio e do incentivo físico e financeiros à pré-escola, possibilitando o atendimento de um número mais elevado de crianças de 4 a 6 anos. Ainda, como uma medida considerada positiva para a democratização do ensino, o governo do Estado buscou uma parceria com os Municípios para a contratação de professores para a $1^{\mathrm{a}}$ a $4^{\mathrm{a}}$ série e construção de novos prédios escolares, totalizando 1.315 prédios escolares construídos entre 1983 a 1986, ainda 
em 1986 as obras em andamento somam 342 prédios, e 125 prédios a iniciar (Paraná, SEED/Fundepar, 1986).

Para o magistério foram oferecidos cursos de capacitação e a realização de concursos e testes seletivos, também foram concedidos benefícios aos professores como reajustes salariais, pagamento do $13^{\circ}$ salário, nomeação de 3.208 professores remanescentes do concurso de 1979, elevação do piso salarial para 3,0 salários mínimos a partir de janeiro de 1985, realização de teste seletivo em janeiro de 1987, entre outras.

Quanto à melhoria da qualidade do ensino, pouco se pôde constatar, visto que os números sobre a repetência e evasão escolar não foram mencionados através de documentos. A despeito dos avanços conquistados em relação ao período do regime militar as ações educacionais do governo em questão, relatadas até o momento, nos indicam - que o prenúncio da apropriação da Pedagogia Histórico-Crítica como fundamento teórico balizador das políticas educacionais, tendo como objetivo a redemocratização escolar - que tal reestruturação educacional constituiu-se num discurso ideológico visando o convencimento/crença em reais transformações no âmbito educacional, ou seja, a concepção teórica da Pedagogia Histórico-Crítica foi utilizada como discurso falado e escrito para simbolizar a transição de uma sociedade autoritária para uma sociedade democrática, ainda que no âmbito dos limites do liberalismo.

\section{Governo Álvaro Dias (1987-1990)}

No governo Álvaro Dias, os pressupostos da política educacional sinalizavam para a democratização do acesso à escola, para a reordenação interna do sistema educacional além de compreender a educação como fator efetivo de mudança social. A partir desses eixos centrais, foram elaborados: o Currículo Básico de Alfabetização; implantado o Ciclo Básico de Alfabetização ${ }^{2}$; correções de idade-série; também foram definidos conteúdos bási-

\footnotetext{
2 "No Ciclo Básico, a alfabetização é o processo de apropriação da língua escrita, o qual deve ser compreendido além do simples domínio do sistema gráfico. (...) Ao propor um novo encaminhamento teórico-metodológico, para a aquisição da linguagem escrita, fez-se ne- 
cos para o ensino denominado de $1^{\circ}$ e $2^{\circ}$ Graus; ampliação do acesso ao $2^{\circ}$ Grau; mudanças ao ensino rural e a educação infantil, além de apoio a educação especial e ao ensino supletivo (Piton, 2004). Ainda nesta gestão iniciou-se o processo de municipalização do ensino primário.

A implantação do Ciclo Básico teve a pretensão de garantir, a um maior número de alunos, a conclusão do ensino de $1^{\mathrm{o}}$ grau, o qual foi especificado pela Lei de Diretrizes e Bases (LDB) 5692/71, como sendo composto de $1^{\text {a a }} 8^{\mathrm{a}}$ série. $\mathrm{O}$ ensino pré-escolar também aparece como uma preocupação da SEED/DEPG, por concebê-la como um direito social. Ainda foram apresentados como objetivos prioritários, a superação da desintegração do $1^{\circ}$ grau, que acarreta altas taxas de evasão e repetência na $5^{\mathrm{a}}$ série, a melhoria do atendimento no ensino noturno, o repensar sobre a concepção de avaliação pedagógica, a integração entre $1^{\circ}$ e $2^{\circ}$ grau, principalmente o magistério, e a reorganização do currículo escolar, proporcionando uma unidade nos programas de ensino coerente com a proposta educacional global. Portanto, para a efetivação dessa proposta de trabalho faz-se necessário a constante capacitação dos profissionais da educação.

Diante do objetivo de reorganizar o currículo escolar de $1^{\circ} \mathrm{Grau}$, foi elaborado o "Currículo Básico de Alfabetização". Publicado em 1990 e distribuído à rede estadual e municipal de ensino em 1991, possibilitou aos professores o acesso aos preceitos teórico-filosóficos da Pedagogia Histórico-Crítica, nas diversas disciplinas, auxiliando na organização da seqüência, ordem e dosagem dos conteúdos de acordo com a série e a disciplina.

Durante essa gestão a relação professor-Estado foi bastante tumultuada. Em 1986, ano anterior a posse do governador Álvaro Dias, os professores conquistaram, após uma greve, o piso salarial de 3 salários mínimos, e essa conquista foi mantida pelo governo apenas de março a setembro de 1987, iniciando então um processo de defasagem salarial. Em conseqüência das perdas salariais, em 1988 deflagrou-se uma greve com reivindicações salariais, as quais não foram atendidas pelo governo do Estado.

cessária a reorganização dos demais conteúdos curriculares das outras séries desse grau de ensino. 
Isso demonstra a contradição existente entre os objetivos anunciados com a implantação do Ciclo Básico, e a atuação do governo do Estado. De um lado anunciava-se a oferta de uma educação científica e de qualidade aos alunos ligada à qualificação profissional dos educadores e sua conseqüente valorização. De outro lado, a prática de desvalorização da categoria do magistério, defasagem salarial, ações autoritárias e violentas para atenuar as reivindicações. Atitudes autoritárias e antidemocráticas, exatamente num momento em que a escola estava sendo anunciada com um espaço democrático.

Diante disso, pode-se afirmar que essa proposta pedagógica, não foi suficiente para lograrmos uma radical revolução. Vários foram os fatores que contribuíram para a não efetivação dessa proposta pedagógica. Um deles foi a oficialização da Pedagogia Histórico-Crítica por parte do Estado, distorcendo seus objetivos e escamoteando suas bases filosóficas de cunho socialista, a partir de uma interpretação de cunho liberal e capitalista. Resultando, conseqüientemente, na má interpretação dessa Pedagogia por parte dos professores que assumiram tal proposta em suas práticas pedagógicas, ou seja, grande número de educadores de todos os níveis de ensino não se apropriaram integralmente dessa teoria, tendo em vista a não compreensão dessa proposta como uma crítica a sociedade capitalista (Nogueira, 1993).

Importa dizer que a Pedagogia Histórico-Crítica não pode ser assumida como uma prática pedagógica apenas pela aplicação metodológica. Deve-se, sobretudo, considerar as condições de trabalho do educador, o ambiente de estudo do educando, a igualdade de condições do processo de ensino/aprendizagem a todos os cidadãos independente da classe social em que pertencem, e por fim a luta pela superação das classes sociais e da concentração de renda.

\section{Governo Roberto Requião (1991-1994)}

No período de 1991 a 1994, o Paraná foi governado por Roberto Requião de Melo e Silva, completando o terceiro mandato consecutivo do PMDB. Nesse governo a escola foi orientada no sentido da autonomia na 
medida em que foi incentivada à elaboração e execução do Projeto Político Pedagógico (construído diferentemente em cada escola), também se fortaleceu o processo de municipalização, foram constituídos os conselhos escolares, a elaboração do Regimento Escolar Único, e a construção do Plano de Capacitação Docente, vinculado ao projeto de Construção da Escola Cidadã no Paraná. Foi ainda nesse período que iniciaram efetivamente as negociações entre o governo do Paraná e as Instituições Multilaterais de Financiamento (BIRD e o BID).

Dentre as ações propostas no programa de governo, várias delas não foram contempladas efetivamente. Como exemplo, entre as ações pedagógicas e de magistério, 'a garantia de um piso salarial profissional para os professores em exercício', 'criação de mais dois níveis na carreira do magistério', 'implantação das escolas de $1^{\circ}$ grau em tempo integral', 'consolidação do Ciclo Básico de Alfabetização', 'maior investimento e atenção à Educação Especial envolvendo aspectos de prevenção', 'identificação e atendimento educacional', só pra citar alguns.

O governo Requião propôs novos métodos e estratégias de trabalho, diferentes daqueles propostos pelos governos anteriores, justificados pela necessidade de superar o anacronismo dos métodos educacionais, e a inovação no sistema de gestão escolar. Para que dessa forma a escola seja adequada às necessidades dos novos indivíduos que nela estão inseridos. Para alcançar tais objetivos, o referido governo afirma haver necessidade de recursos externos, os quais garantam o início desse processo de inovação educacional.

Apesar do programa de governo de Roberto Requião apresentar propostas que pretendiam-se inovadoras, como a construção do "Regimento Escolar Único", criação do "Conselho Escolar", "plano estadual de capacitação de docente", "implantação do Ciclo Básico de 4 anos", proposta de elaboração do "Projeto Político-Pedagógico", entre outras, esse governo foi conflituoso com os trabalhadores da educação. Primeiramente, pelo fato de que os cursos de capacitação, nos quais cada professor deveria participar de no mínimo 80 horas, não estavam articulados a um projeto mais amplo, e ainda a acentuada defasagem salarial. 
A concepção da Pedagogia Histórico-Crítica, que esteve presente nas políticas educacionais dos governos peemedebistas que antecederam ao governo de Requião, não foi contemplada nas políticas educacionais desta última gestão. Haja visto que as orientações advindas da SEED consubstanciavam a pluralidade de visões teóricas (ecletismo), defendendo a elaboração de um método de conhecimento do cotidiano da escola (espontaneísmo), onde ela própria irá refletir sobre suas problemáticas e a partir de então, propor novos projetos de trabalho como alternativa para solucionar os reais problemas. Contudo, os professores são incentivados pela SEED, a elaborarem projetos pedagógicos inovadores inspirados em "boas idéias" que acreditam ser possível de implementá-las, concretizá-los e em seguida relatá-lo aos demais docentes, através de um seminário de troca de experiências promovido pela SEED.

Essa forma, individualista e espontânea, de organizar o trabalho pedagógico que propõe ao professor a tarefa de criar alternativas inovadoras e salvacionistas da educação, deixa nas mãos do professor e da escola a responsabilidade de melhorar a qualidade do ensino público. Uma vez que o educador já foi responsabilizado pelo fracasso escolar, e em função disso foram criadas as premiações como forma de incentivar os docentes a qualificarem-se e inovarem em seu trabalho. Pois, o fracasso escolar foi considerado pelo Superintendente da Educação, Antônio João Mânfio, mais um problema psicológico do que real (afirmação explicitada no documento "Paraná: Construindo a Escola Cidadã").

Sendo assim, entende-se que para superar o fracasso e obterem o sucesso na educação, basta olhar para o professor, exigir dele que participe de cursos de qualificação profissional e em conseqüência espera-se que ele exerça seu trabalho pedagógico de forma inovadora e de qualidade. Isso tudo sem questionar as precárias condições de trabalho do professor, a baixa remuneração, o reduzido tempo para estudo e preparação de aulas, além da ausência de um Projeto Educacional da SEED e a desqualificação histórica do profissional da educação. O que por detrás de um discurso de autonomia, interdisciplinaridade e pluralismo cultural, acarreta no individualismo, na 
desarticulação pedagógica e em ações espontaneístas, suprimindo a cientificidade necessária à educação.

Defendemos, portanto, a relevância de uma concepção pedagógica científica e de uma política educacional unitária, por entender que a garantia para a efetiva realização da função social da escola está na definição de uma concepção de homem, sociedade, educação e de escola para nortear o desenvolvimento do trabalho docente. Portanto, aquilo que deve ser ensinado na escola refere-se a cultura erudita, clássica, não restringindo-se apenas a conhecimentos de uma determinada cultura, região ou língua.

\section{Matriz política e teórica da Pedagogia histórico-crítica}

Em meados dos anos de 1970, diante de um cenário de repressão e desmobilização dos grupos de educadores e estudantes, inicia-se na área da educação, análises críticas referentes ao modelo de sociedade concreta, sobretudo ao modelo capitalista. Nesse período verifica-se a influência de autores diversos como Bourdieu e Passeron, e marxistas como Althusser, Poulantzas e Gramsci.

Essas concepções críticas foram denominadas por Saviani (1995) como teorias crítico-reprodutivistas. As quais entendem a educação como um instrumento de discriminação social, acentuando o problema da marginalidade. Essas teorias são críticas por compreenderem a educação relacionada com os condicionantes sociais, ou seja, sendo determinada pela sociedade. No entanto, são denominadas de reprodutivistas por empenharem-se apenas em explicar os mecanismos de funcionamento da escola enquanto reprodutora das relações sociais capitalistas, não possuindo uma proposta pedagógica de superação dessa condição.

Para se contrapor às teorias não-críticas e crítico-reprodutivistas, Saviani empenhou-se, desde a década de 1970, em formular uma teoria que "se impõe à tarefa de superar tanto o poder ilusório (que caracteriza as teorias não-críticas) como a impotência (decorrente das teorias críticoreprodutivistas) colocando nas mãos dos educadores uma arma de luta capaz de permitir-lhes o exercício de um poder real, ainda que limitado" (Saviani, 
1995, p. 41). Essa teoria denominou-se Pedagogia Histórico-Crítica, a qual é uma concepção revolucionária de educação, correspondente à ideologia da classe trabalhadora, que visa à superação das desigualdades, contrapondo-se a visão liberal burguesa.

Quanto às bases teóricas da Pedagogia Histórico-Crítica, encontramos seu fundamento no materialismo histórico-dialético de Marx. Este método pedagógico leva em conta a importância de vincular a teoria à prática (práxis), e que a função da educação é exatamente a articulação proposta de unificar esta práxis, fazendo com que o aluno seja transposto do conhecimento empírico para o concreto pensado ${ }^{3}$.

A referida teoria crítica da educação tem por finalidade defender os interesses da classe trabalhadora. Seu objetivo maior é o de transmitir aos trabalhadores os conhecimentos clássicos, eruditos, para que assim eles tenham condições de igualar seus conhecimentos com os da classe dominante, e conseqüentemente, lutar para libertar-se da exploração e dominação.

A educação escolar não pode resumir-se em trabalhar com conteúdos cotidianos, deixando de lado o científico. Pois ao esvaziar a escola de conteúdos clássicos, tira-se sua principal função, que é a de possibilitar aos sujeitos, a partir do conhecimento político, filosófico e científico, transformarem sua consciência e conseqüentemente seus atos. Apesar da grande importância dada aos conteúdos não podemos classificar tais teorias como conteudistas, um pejorativo criado por detratores, haja vista sua preocupação com a forma, ou seja, com a metodologia utilizada ao transmitir os conhecimentos.

\footnotetext{
3 "O concreto é concreto porque é a síntese de muitas determinações, isto é, unidade do diverso. Por isso o concreto aparece no pensamento como processo da síntese, como resultado, não como ponto de partida efetiva e, portanto, o ponto de partida também da intuição e da representação. (...) por isso é que Hegel caiu na ilusão de conceber o real como resultado do pensamento que se sintetiza em si, se aprofunda em si, e se move por si mesmo; enquanto que o método que consiste em elevar-se do abstrato ao concreto não é senão a maneira de proceder do pensamento para se apropriar do concreto, para reproduzilo como concreto pensado". (Marx, 1986, pp. 16-17).
} 
Como prova da importância dada ao método de ensino, Saviani (1995, p. 79-80-81) elaborou cinco passos ${ }^{4}$ fundamentais a serem observados desde o planejamento até a prática de uma aula.

O ponto de partida seria a prática social ( $1^{\circ}$ passo), que é comum a professor e alunos. (...) segundo passo: problematização (...) trata-se de detectar que questões precisam ser resolvidas no âmbito da prática social e, em consequiência, que conhecimento é necessário dominar. (...) terceiro passo instrumentalização (...) trata-se da apropriação pelas camadas populares das ferramentas culturais necessárias à luta social que travam diuturnamente para se libertar das condições de exploração em que vivem. (...) quarto passo catarse (...) trata-se da efetiva incorporação dos instrumentos culturais, transformados agora em elementos ativos de transformação social. (...) e quinto passo o ponto de chegada é a própria prática social (...) neste ponto, ao mesmo tempo que os alunos ascendem ao nível sintético em que, por suposto, já se encontrava o professor no ponto de partida, reduz-se a precariedade da síntese do professor, cuja compreensão se torna mais e mais orgânica.

Tendo em vista essa metodologia de trabalho, fica claro que para a Pedagogia Histórico-Crítica a escola não é vista como transformadora da sociedade, e sim, é considerada como necessária e mediadora para o processo de transformação, o qual se dará através das ações revolucionárias dos cidadãos. Como tal, além da preocupação com o conteúdo e com a forma em que ocorre o processo de ensino aprendizagem, as teorias críticas dão atenção especial aos alunos, os quais são vistos mediante uma concepção dialética de homem e sociedade ${ }^{5}$. Contudo, é mister destacar que o aluno não é concebido como na visão Tradicional, onde a criança/aluno era compreendida de forma abstrata, como um adulto em miniatura, um ser inacabado que possui um potencial inato e que precisa ser desenvolvido, tendo o

4 Os cinco passos elaborados por Saviani foram desenvolvidos de forma sistematizada, por Gasparin (2002) no livro Uma didática para a Pedagogia Histórico-Crítica.

5 A presente análise sobre a concepção de homem identificada nas diferentes correntes pedagógicas se dá a partir do estudo de ZANELLA, J.L. A educação da criança na Pedagogia Histórico-Crítica, 2006. 
educador a função de moldar a criança desenvolvendo os potenciais que cada um possui dentro de si. Tampouco, a Pedagogia Histórico-Crítica compreende o aluno como na Pedagogia Nova, a qual concebe o aluno de forma empírica, ou seja, valoriza o sentimento, o psicológico, as vontades, e necessidades dos educandos. Dessa forma defendem o desenvolvimento da criança a partir da liberdade, da espontaneidade (Pedagogia da espontaneidade, nascida com Rousseau), concretizando-se na negação da diretividade e do ensino.

Na Pedagogia Histórico-Crítica, o educando é concebido de forma concreta, que é diferente de empírico. Compreender o aluno de forma concreta nessa perspectiva significa conceber o homem como síntese de múltiplas determinações, como resultado do movimento histórico produzido pela humanidade. É compreender a criança/aluno na sua totalidade, entender que os sentimentos e vontades dos homens, não são apenas necessidades psicológicas e/ou biológicas, e sim sociais. Somos aquilo que fazemos no meio em que vivemos, ou melhor, somos produzidos mediante o meio em que nos encontramos.

Mas qual é o motivo pelo qual as teorias críticas não têm espaço no âmbito educacional? Por que elas são facilmente distorcidas? Por que o Estado, enquanto instituição responsável pela educação, não assume estas concepções como oficiais, ou quando assume essas propostas não saem totalmente do papel?

O fato é que essas concepções críticas de educação não são compatíveis com os ideais capitalistas, portanto não são possíveis de serem aplicadas igualmente nessa sociedade. Como visto anteriormente, trata-se de uma proposta de educação que visa à transformação desse modelo de sociedade, dito de outra forma, tal teoria objetiva a superação do modo de produção capitalista por um modelo socialista de sociedade.

Esses fatores contribuem para dificultar que esta concepção saia do papel, quando escolhida como teoria educacional oficial de Estado. Também é facilmente distorcida devido à falta de conhecimento científico ensinado pela escola, tanto nos níveis fundamental e médio, como na academia. Visto que sem conhecer profundamente a teoria dos clássicos torna-se mais difícil 
ter condições de analisar criticamente as inúmeras produções difundidas no âmbito educacional. O que contribui para a manutenção da alienação, nos deixando seduzidos pelos modismos que freqüentemente se interpõem na prática pedagógica.

Partiremos agora para o estudo da matriz política da referida concepção de educação. Fazendo uma análise conjuntural do processo histórico da elaboração da Pedagogia revolucionária até sua apropriação como política educacional de governo, ocorrido no Estado do Paraná nos anos 1980, pretenderemos esboçar as diretrizes finais do presente capítulo.

A Pedagogia Histórico-Crítica teve início nos anos de 1970, como uma pedagogia revolucionária em defesa da classe trabalhadora e da escola como espaço de transmissão do saber erudito, construído pelo conjunto dos homens em suas relações históricas, em prol da transformação social. Porém faz-se necessário compreender quais os fatores que pressupõem a implantação da Pedagogia Histórico-Crítica na educação escolar brasileira.

O Estado na ótica liberal constitui-se no Estado que justifica a organização burguesa de sociedade. O Estado é um órgão representativo da sociedade civil, no entanto, a sociedade civil constitui-se cindida em classes sociais antagônicas, onde uma delas indica seus representantes políticos e, conseqüentemente, passa ter o Estado como representante dos seus interesses. O Estado, nesta lógica, constitui-se num instrumento a serviço da classe dominante com o objetivo de alcançar a hegemonia do ideário burguês.

Para atingir o consenso sobre a ideologia burguesa, a escola passa a ser utilizada como espaço de dissimulação e perpetuação dessa falsa consciência de igualdade. Segundo Gramsci, não só a escola é utilizada como reprodutora da hegemonia capitalista a partir de forças que objetivam a manutenção do status quo, como o próprio Estado é constituído por um Estado Educador.

O Estado liberal é determinado pela concepção liberal de sociedade, de homem e de trabalho, o Estado que faz das políticas públicas um serviço prestado na ótica do mercado, tende a torná-lo acessível como mercadoria, portanto, a quem pode pagar. E ainda constituindo-se o Estado em Estado mínimo, racionaliza recursos financeiros, meios, trabalho, de tal forma a 
tornar a educação e o trabalho pedagógico eficientes apenas na ótica do mercado. Portanto, torna-se difícil a implantação de uma concepção revolucionária de homem, sociedade e educação, numa sociedade liberal que partilha de outro modelo de sociedade, e conseqüentemente, de outra concepção de homem, de trabalho, sociedade, conhecimento e de educação.

Em contrapartida ao Estado liberal, temos o Estado Revolucionário, o qual se opõe ao primeiro por partir fundamentalmente da crítica a estrutura social burguesa. A concepção revolucionária de Estado tem como objetivo a superação da sociedade capitalista por uma sociedade organizada pelo modo de produção socialista, sobretudo pela superação da propriedade privada e da exclusão do acesso aos direitos dos cidadãos, e superação da sociedade cindida em classes antagônicas.

A Pedagogia Histórico-Crítica fundamenta-se nos princípios de uma educação revolucionária, onde todos os cidadãos possuem direito ao acesso a uma educação pública, de qualidade e igualitária. Portanto, para sua implantação, necessita-se de um Estado também com princípios revolucionários, e de uma sociedade civil não mais composta por grupos antagônicos, individualistas, excludentes, em busca de maior poder político sobre os demais grupos ou classes sociais.

Para a implantação da Pedagogia Histórico-Crítica, além de um Estado Revolucionário, necessita-se de um Plano Nacional de Educação. Pois esta Pedagogia não pode ser entendida apenas como uma teoria educacional e nem mesmo sua implantação pode ser realizada apenas como recursos metodológicos a serem aplicados em sala de aula. Esta é uma concepção pedagógica que pressupõe uma alteração na organização do Estado, na concepção de educação e numa organização da educação em âmbito nacional. Não pode ser usada como uma política educacional de governo, sem que as estruturas básicas da educação escolar sejam modificadas.

A presente análise nos conduz à compreensão de que a implantação da Pedagogia Histórico-Crítica somente faria sentido se levada a termo pela sociedade civil organizada, pelos movimentos sociais como instrumento de formação da classe trabalhadora para promover a antítese do Estado liberal, para desfazer a alienação imposta e em sentido mais amplo somente poderia 
ser utilizada pelo Estado quando a sociedade civil constituir o estado representante da classe trabalhadora como meio para promover sua superação e a constituição da sociedade sem classes.

A partir dessa digressão histórica e filosófica, ainda que de forma breve e circunscrita aos limites desse trabalho, do percurso político e contextual das idéias pedagógicas presentes na história da educação brasileira até a elaboração da Pedagogia Histórico-Crítica, definiremos nossas possíveis conclusões sobre o processo de apropriação da Pedagogia HistóricoCrítica, como proposta educacional nos governos peemedebistas (19871994) no Estado do Paraná, além das respectivas contradições e perspectivas existentes nesse período de implantação.

\section{Análise crítica da implantação da Pedagogia histórico-crítica no Es- tado do Paraná: processos institucionais, contradições e perspectivas}

Conforme constatado na análise exposta anteriormente, a implantação da Pedagogia Histórico-Crítica no Estado do Paraná se deu por interesse do estado em obter a hegemonia e o consenso, não se constituindo, no entanto, numa escolha da classe trabalhadora diante das suas reais necessidades e interesses. Portanto, esses fatores demonstram que a ação do estado foi autoritária e oportunista, quando da utilização da referida pedagogia crítica de educação, por utilizá-la como uma manobra para alcançar os ideais de dominação e expansão do capital, preestabelecidos nesse processo de redemocratização social, tendo como meta atender de forma individual e ideológica os interesses e necessidades do capital.

Foi autoritária ao implantar uma teoria revolucionária - de cima para baixo - com o intuito de convencer a comunidade escolar de que o estado realmente estaria revolucionando a educação através de ações democráticas e teorias críticas. Dessa forma o estado foi oportunista e antecipou-se aos professores, fazendo uma revolução motivada por um discurso revolucionário e transformador. Mas que não passou de um discurso não materializado.

Ações insuficientes que demonstram a superficialidade e inconsistência material na implantação da Pedagogia Histórico-Crítica, presentes 
num discurso progressista que na prática foi incapaz de produzir reais transformações nas condições materiais na base da sociedade. Foi superficial quando a implantação da Pedagogia Histórico-Crítica reduziu-se a um método pedagógico, a uma forma de organizar conteúdos curriculares científicos e transformá-los em saber escolar.

Além desses fatores, tal implantação foi inconsistente, pois manteve intacta a organização escolar em disciplinas fragmentadas, carga horária elevada de trabalho do professor e a não remuneração das horas de trabalho fora da sala de aula. A capacitação docente configurou-se numa perspectiva eclética e o apoio da SEED aos docentes foi insuficiente no momento de implantações de novos métodos e teorias pedagógicas. O que reafirma a preocupação manifestada aos métodos de ensino e a prática pedagógica em detrimento das condições materiais de trabalho.

Diante desse quadro é possível destacar as contradições entre a implantação de uma pedagogia crítica como proposta educacional de governo e, as ações desse mesmo governo, as quais divergem dos objetivos propostos pela concepção pedagógica histórico-crítica. Visto que a Pedagogia Histórico-Crítica, diante do seu caráter revolucionário, propõe que a educação seja estruturada de tal forma que possibilite aos alunos a apropriação dos conteúdos científicos, munindo-os de conhecimento que os capacite para atuarem na sociedade de forma transformadora, e não de maneira reprodutora e alienada.

Para se alcançar os objetivos da Pedagogia Histórico-Crítica necessita-se de transformações reais, materiais e estruturais da organização escolar. Trata-se de nova forma de conceber os objetivos sociais da educação, de financiar a educação pública e organizar a escola para todos. Sendo assim, a forma de trabalho no processo de ensino-aprendizagem deve ser apenas um dos fatores a serem modificados, e não o único. Pois, para que o professor consiga preparar uma aula de acordo com os passos metodológicos propostos por Saviani, ele necessitará de muito conhecimento científico apoiado em materiais pedagógicos diversos. O que ressalta a necessidade de tempo para preparação das aulas e estudo científico, além de um acervo bibliográfico que dê sustentação tanto no estudo como na prática pedagógica. 
Diante do contexto analisado, é possível afirmar que a implantação da Pedagogia Histórico-Crítica pelo governo do estado do Paraná não passou de um impulso de idealismo pedagógico necessário naquele momento de redemocratização da sociedade aos produtores do novo consenso político conjuntural. Quer dizer, num momento em que a sociedade clamava por uma revolução e superação da opressão, do autoritarismo e da falta de liberdade, o grupo que assume o poder na promessa de superação das condições de trabalho e de vida impostas pelo regime militar, tem como compromisso político com a sociedade apresentar propostas renovadoras e até revolucionárias.

Mas o grupo que assume o poder não tem a pretensão de fazer revoluções que extrapolem os limites impostos pelo capital. Visto que a intenção continua sendo a de manutenção e reprodução do modo de produção capitalista. Aí está o motivo pelo qual a Pedagogia Histórico-Crítica foi implantada apenas como um discurso político, não sendo alterada significativamente a estrutura organizacional da educação escolar paranaense.

Apesar de o Estado ter assumido essa Pedagogia como política educacional oficial, não foi possível perceber sua efetiva implantação. Quer dizer, o Estado ao assumir a proposta de redemocratização da sociedade assim como da educação, não o faz desvinculado do projeto Liberal de Estado capitalista. Portanto, não é possível uma Pedagogia de caráter revolucionário, que tem em suas bases a pretensão a superação da sociedade capitalista por uma sociedade de organização socialista, ser implantada de forma integral pelas mãos do Estado.

Mesmo a Pedagogia Histórico-Crítica tendo sido apropriada de forma idealista e sem a pretensão de alcançar reais transformações educacionais e consequentemente sociais, ela continua sendo uma teoria revolucionária, crítica e orgânica da classe trabalhadora. Por ser, sobretudo, uma teoria orgânica da classe trabalhadora, sua implantação deve ter início no seio desta classe, representada pelos profissionais da educação. Deve ser implantada de baixo para cima, como uma conquista resultante da luta de classes, tendo como pretensão maior a superação das desigualdades sociais e de direitos tanto da saúde como da educação. 
Em suma, a Pedagogia Histórico-Crítica é a construção referencial cumulativa de um novo projeto social e educacional para o Brasil e, desse modo, para o Paraná. Mas sua vitalidade reside justamente em sua capacidade analítica de desvendar as intenções alienantes e mistificadoras para dar vazão à determinação política de se produzir no Brasil uma real mudança no papel do estado, na sistematização dos objetivos públicos da educação e da escola e na construção de um novo homem e um novo mundo, marcado pela formação omnilateral e pela conquista dos consensos sociais e subjetivos plenos.

A Pedagogia Histórico-Crítica apresenta-se ainda como o horizonte inspirador de necessárias e urgentes transformações no perfil estrutural da educação e da escola no Brasil. Mas esse horizonte não se conquista com determinações normativas ou dispositivos reguladores, mas sim com sistematizações jurídicas que nasçam de novos ordenamentos sociais e políticos, nucleados na plena participação das camadas sociais marginalizadas e que, por essa razão, trazem em si a novidade da humanização, universalização e natureza distributiva e isonômica das mudanças educacionais.

\section{Referências bibliográficas}

CUNHA, L.A. Educação, Estado e democracia no Brasil. 2. ed. São Paulo: Cortez; Niterói, RJ: Editora da Universidade Federal Fluminense; Brasília, DF: FLACSO do Brasil, 1995. (Biblioteca da educação. Série 1. Escola; v. 17).

GASPARIN, J.L. Uma didática para a pedagogia histórico-crítica. Campinas, SP: Autores Associados, 2002.

GONÇALVES, M.D. de S. Autonomia da escola e neoliberalismo: Estado e escola pública. São Paulo. Pontifícia Universidade Católica de São Paulo, 1994 (Tese de Doutorado).

GRAMSCI, Antônio. Os intelectuais e a organização da cultura. Tradução de Carlos Nelson Coutinho. 9.ed. Rio de Janeiro: Civilização Brasileira, 1995. 
MAINARDES, Jefferson. Ciclo básico de alfabetização: da intenção à realidade. (Avaliação do CBA no Município de Ponta Grossa - PR). Campinas, SP: UNICAMP, 1995 (Tese de Doutorado).

MARTINS, Rosilda Baron. Escola cidadã do Paraná: análise de seus avanços e retrocessos. Campinas, SP: UNICAMP, 1997 (Tese de Doutorado).

NAGLE, Jorge. Educação e sociedade na Primeira República. - 2a ed. - Rio de Janeiro: DP\&A, 2001.

NOGUEIRA, F.M.G. Politicas educacionais do Paraná: uma versão institucional da proposta pedagógica dos anos oitenta. São Paulo: Pontifícia Universidade Católica de São Paulo, 1993 (Dissertação de Mestrado).

PARANÁ. Secretaria de Estado da Educação. Politicas SEED - PR; fundamentos e explicitação. 3. ed. Curitiba: SEED, 1984.

. Secretaria de Estado da Educação. Projeto Pedagógico: 1987 - 1990. Curitiba: SEED, 1987.

. Secretaria de Estado da Educação. Currículo Básico Para a Escola Pública do Estado do Paraná. Curitiba, PR: SEED, 1990.

. Secretaria de Estado da Educação. Superintendência de Educação. Paraná: construindo a escola cidadã. Curitiba: SEED, 1992.

PMDB. Diretrizes de Governo: Politica de Educaşão. (José Richa). Curitiba, 1982.

. Diretrizes de Governo para debates - Governo Álvaro Dias. Curitiba, 1986.

- Uma educaşão para a modernidade - propostas de ações governamentais para o ensino do Paraná. (Roberto Requião). Curitiba, 1990.

PITON, I.M. Políticas educacionais e movimento sindical docente: reformas educativas e conflitos na educação básica paranaense. Tese de doutorado, Faculdade de Educação da Universidade Estadual de Campinas - UNICAMP, 2004.

SAVIANI, D. Escola e democracia. 30. ed. Campinas, SP: Autores Associados, 1995.

. Educação: do senso comum à consciência filosófica. 14. ed. - Campinas, SP: Autores Associados, 2002.

Pedagogia histórico-critica: primeiras aproximações. $8^{\mathrm{a}}$ ed. Campinas, SP: Autores Associados, 2003.

ZANELLA, J. L. O trabalho como principio educativo do ensino. Campinas, SP: editora da Unicamp (Tese de doutorado), 2003. 
WACHOWICZ, Lílian Anna. A questão do saber e da escola na concepção de

Dermeval Saviani. In. Dermeval Saviani e a educação brasileira: o simpósio de Marília. São Paulo: Cortez, 1994. 